\title{
Investigating Earth Reaction to Pull-Out Process of Frictional Rock Bolts Using Distinct Element Method
}

\author{
Mohammad Sadegh Ayyoobi, Arash Refahi* \\ Mining Department, Faculty of Engineering, University of Zanjan, Zanjan, Iran \\ Email:mohamadayobis@yahoo.com, ${ }^{*}$ refahi.arash@znu.ac.ir, refahi.arash@gmail.com
}

How to cite this paper: Ayyoobi, M.S. and Refahi, A. (2020) Investigating Earth Reaction to Pull-Out Process of Frictional Rock Bolts Using Distinct Element Method. Open Journal of Geology, 10, 851-862. https://doi.org/10.4236/ojg.2020.108038

Received: July 1, 2020

Accepted: August 4, 2020

Published: August 7, 2020

Copyright $\odot 2020$ by author(s) and Scientific Research Publishing Inc. This work is licensed under the Creative Commons Attribution International License (CC BY 4.0).

http://creativecommons.org/licenses/by/4.0/ (c) (i) Open Access

\begin{abstract}
The reaction of earth to pull-out process of frictional rock bolts was here modeled by the distinct element method (DEM). Ten frictional bolts were prepared; the expanding shells of five bolts included convex edges and the others had the shells with concave bits. The strength of bolts was measured by applying a standard pull-out test; the results confirmed that the strength of shells with convex edges was remarkably more than the strength of other shells. Furthermore, a two-dimensional DEM model of the test was developed by a particle flow code; the obtained results showed that the reaction of rock particles to the contacts occurring between the convex edges and earth was considerably more than those of the concave bits. In the other words, the convex edges transferred the pull-out force into a large area of the surrounded rock, causing these bolts to have the highest resistance against earth movements.
\end{abstract}

\section{Keywords}

Frictional Rock Bolt, Pull-Out Test, Distinct Element Method, Particle Flow Code

\section{Introduction}

In order to increase the stability of rock structures, rock bolt systems have been developed dramatically for 50 years; they were designed for variety ranges of underground spaces and ground slopes. A rock bolt consists of a steel rod that is located in a hole and stuck mechanically or chemically to the inner wall of hole, so it is tensioned to transfer the applied loads to rock particles using the established contacts during earth movements (Figure 1). On the other hand, the 


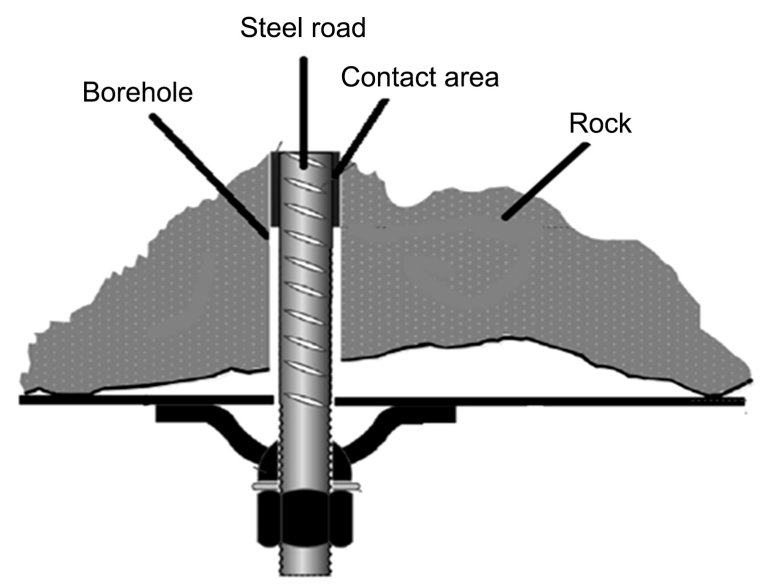

(a)

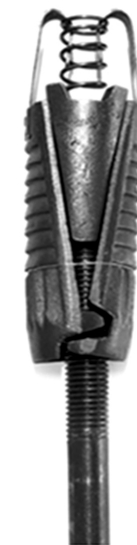

(b)

Figure 1. (a) A frictional rock bolt; (b) An expansion-shell-rock bolt [8].

contact strength must be high enough to tolerate dead weights of rocky roofs [1]-[12]. In this study, the performance of expansion-shell-rock bolts was investigated numerically. These bolts that belong to frictional categories make contacts with hole walls by expanding steel shells that include convex edges or concave bits, as shown in Figure 1 [8]. For this purpose, a standard pull-out test has been applied to the installed bolts, and then, reactions of earth to the pull-out process of bolts were modeling numerically by distinct element method (DEM).

The DEM was developed for modeling discrete systems that include all numerical methods treating the problem domain as an assemblage of independent units. It is mainly applied to the problems of fractured rocks, granular media, concrete and multi-body systems in mechanical engineering. The Particle Flow Code in two Dimensions (PFC2D) based on DEM was adopted to model the corresponding pull-out tests; the rocky wall of holes was modeled as an assembly of rigid particles bonded together. Also, to verify the obtained results, the pull-out strengths acquired from DEM modeling were compared to those estimated from the experimental tests [13] [14] [15] [16].

\section{Materials and Methods}

To simulate the rocky environment surrounding rock bolts, a cubic block of concrete with $0.5 \times 0.7 \times 1 \mathrm{~m}$ in dimensions was prepared and 10 holes with 45 $\mathrm{mm}$ in diameter and $0.85 \mathrm{~m}$ in depth were drilled as shown in Figure 2. The block was shaped in a cubic-wooden mold; fine-grained sand and Portland cement (type 2) were mixed with water and poured into the mold. After 28 days, which the concrete reached the final resistance, five frictional bolts with the shells included convex edges (Figure 3(a)) and five bolts including concave bits (Figure 3(b)) on their shells were installed into the holes. The contact length between the shells and hole wall was 10 and $40 \mathrm{~cm}$, for convex edges and concave bits respectively [17] [18] [19] [20]. Table 1 shows the physical and mechanical properties of studied bolts. 


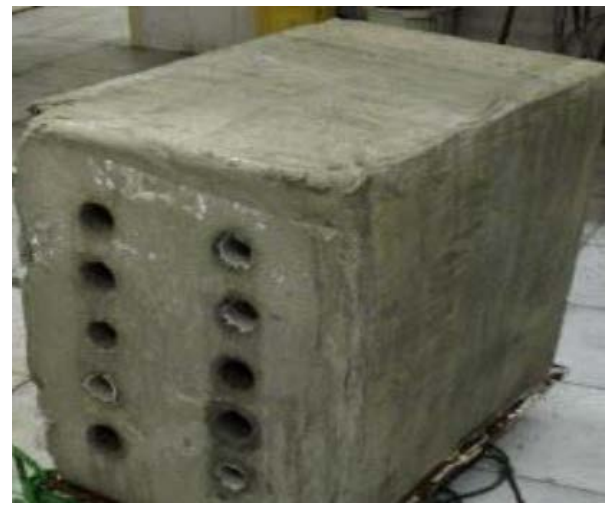

Figure 2. Concrete block including 10 holes.

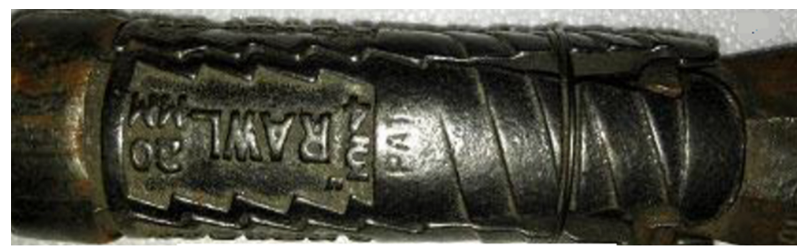

Shells with convex edges

(a)

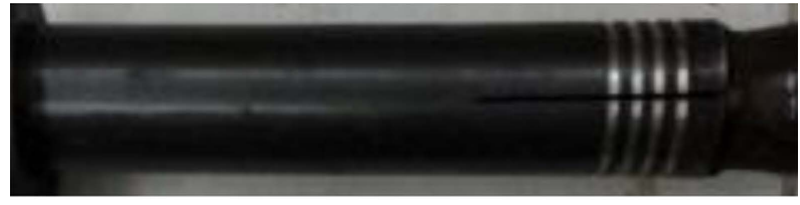

Shells with concave bits

(b)

Figure 3. (a) Shells of studied bolts with (a) convex edges and (b) concave bits.

Table 1. Properties of rock bolts.

\begin{tabular}{ccc}
\hline Property & $\begin{array}{c}\text { Rock bolt with shells include } \\
\text { convex edges (RB-M24) }\end{array}$ & $\begin{array}{c}\text { Rock bolt with shells include } \\
\text { concave bits (R-DCA-A4) }\end{array}$ \\
\hline Inner diameter $(\mathrm{mm})$ & 20 & 20 \\
Outer diameter $(\mathrm{mm})$ & 25 & 25 \\
Length $(\mathrm{mm})$ & 1000 & 5000 \\
Tensile strength of steel road (MPa) & 500 & \\
\hline
\end{tabular}

Based on the D 4435-84 ASTM standard [19], a standard pull-out test was carried out on the installed bolts using ENERPAC_RRH SERIES hydraulic jack with 60 tons in capacity as shown in Figure 4. Table 2 gives the obtained results from each test; the mean pull-out strength (maximum pull-out force) of bolts with shells including convex edges and concave bits are equal to $38 \mathrm{KN}$ and 200 $\mathrm{N}$, respectively. It is clear that, the strengths of shells with convex edges are significantly higher than that of shells including concave bits. Because the edges can 


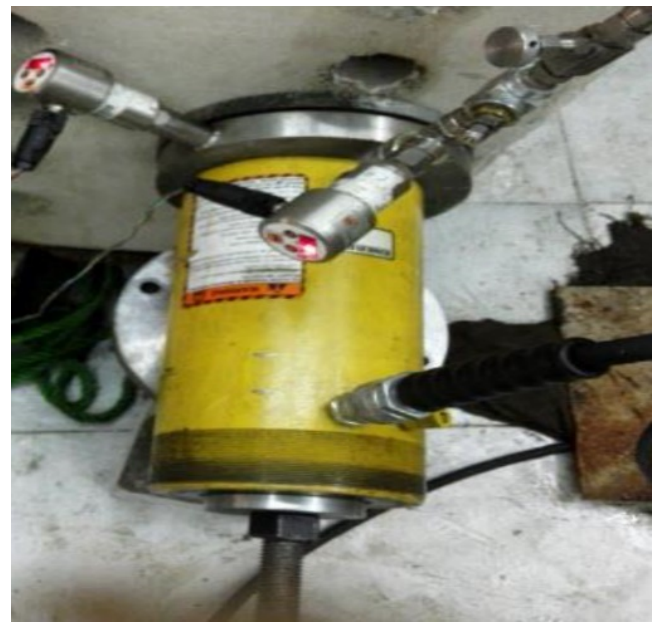

Figure 4. ENERPAC_RRH SERIES hydraulic jack.

Table 2. Rock bolt strengths measured from pull-out test.

\begin{tabular}{cccc}
\hline Rock bolts with shells include convex edges & Rock bolts with shells include concave bits \\
\hline Bolt number & $\begin{array}{c}\text { Maximum pull-out } \\
\text { force (KN) }\end{array}$ & Bolt number & $\begin{array}{c}\text { Maximum pull-out } \\
\text { force (KN) }\end{array}$ \\
\hline 1 & 59.1 & 1 & 0.23 \\
2 & 89.3 & 2 & 0.15 \\
3 & 19.6 & 3 & 0.13 \\
4 & 10.2 & 4 & 0.23 \\
5 & 10.1 & 5 & 0.26 \\
\hline
\end{tabular}

penetrate into the inner wall holes and transfer pull out forces to the surrounded environment very well, so a high frictional resistance occurs remarkably. However, this process did not happen for the shells with concave bits. Figure 5 shows the curve of pull-out force-displacement that was obtained from the test [17] [18] [19].

\section{Distinct Element Method}

In order to examine the reaction between the earth and shells of bolts, a granular model has been developed by the particular flow code in two dimensions (PFC2D), which is based on the distinct-element-method (DEM). The software models the mechanical behaviors of rigid particle assemblies; particle interactions are treated as dynamic processes with states of equilibrium developing whenever the internal forces reach a balance condition. The contact forces and displacements of particles are traced by a time-stepping algorithm; the chosen time step is very small to prevent the spread of disturbance among the particles. In each calculation step, the forces acting on each particle are determined in the point contacts using the force-displacement law, and then Newton's law is used 


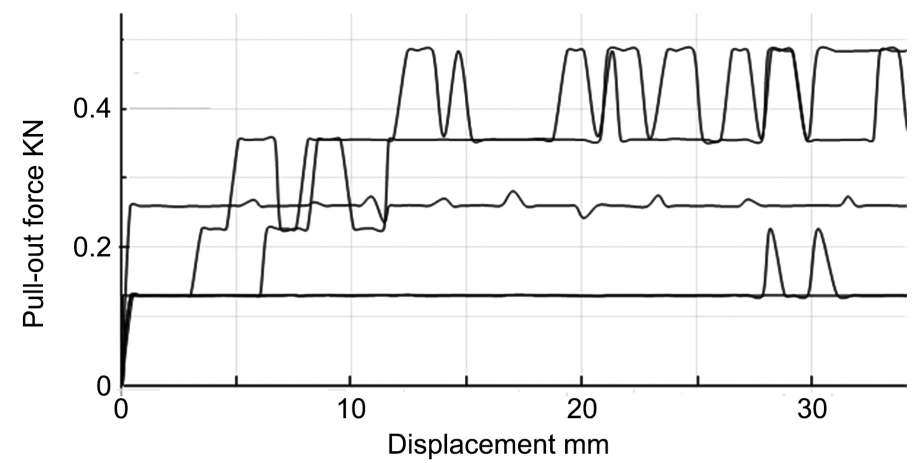

(a)

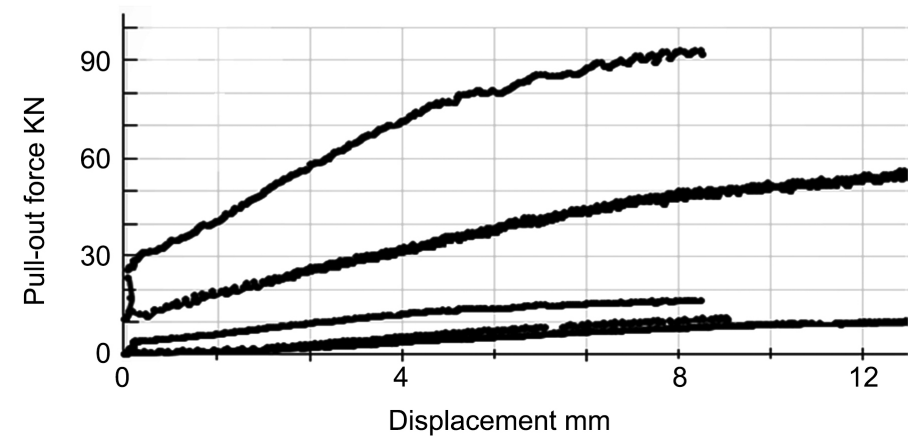

(b)

Figure 5. Experimental pull-out force-displacements obtained from the test for rock bolts with shells including (a) concave bits and (b) convex edges.

to determine the motion of each particle arising from the contact and body update the new position and contacts of particles. The properties of a distinct system which are called micro-mechanical properties are divided into two categories related to contacts and bonds between particles. As shown in Figure 6, a new contact occurs when the distance between two bodies decreases to the critical value. By assuming linear springs with a constant normal $\left(K^{n}\right)$ and shear stiffness $\left(K^{s}\right)$ at the point contact, a linear force-displacement model is developed for it; the created contact force due to deformation of springs is divided to normal and shear components. Also, dashpots with a constant viscosity are used to decrease kinetic energies in static problems. The linear springs cannot sustain tension, however, a slip can be investigated by comparing the shear and frictional forces (Figure 7) [13] [14] [15] [16].

If the relative displacement increment at the contact during a time step is given by $\Delta \delta_{n}$ (the normal component) and $\Delta \delta_{s}$ (the shear component), the liner normal and shear contact force ( $F^{n}$ and $F^{n}$, respectively) will be equal to:

$$
\begin{aligned}
& F^{n}= \begin{cases}F_{0}^{n}+K^{n} \Delta \delta_{n} & \text { if } \Delta \delta_{n} \leq 0 \\
F_{0}^{n}+0 & \text { if } \Delta \delta_{n} \geq 0\end{cases} \\
& F^{s}=F_{0}^{s}-K^{s} \Delta \delta_{s}
\end{aligned}
$$

where $F_{0}^{n}$ and $F_{0}^{s}$ are the linear normal and shear forces at the beginning of the time step, respectively. The micro-mechanical parameters input to the code 


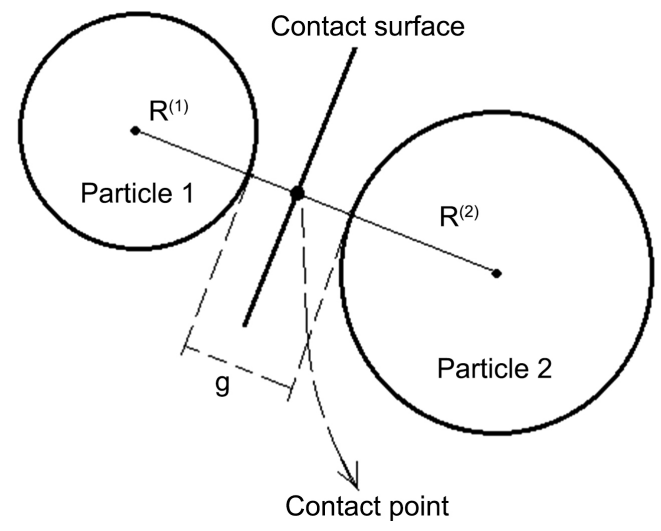

Figure 6. A contact between two rigid particles [14].

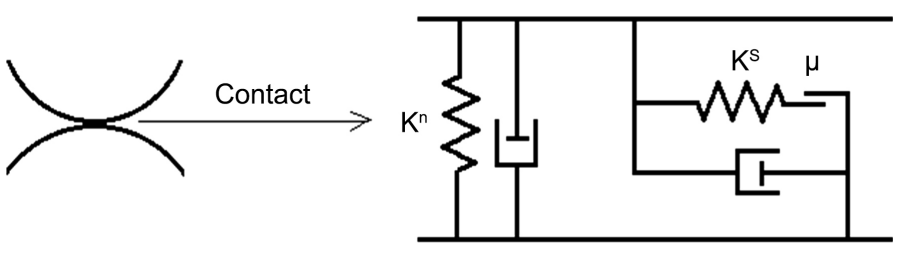

Figure 7. Springs and dashpots modeling a linear contact [14].

are Young modulus (E), friction coefficient ( $\mu$, for Coulomb limit), and normal-to-shear stiffness ratio $(\alpha)$ of contacts. The stiffnesses are calculated by [13] [14] [15] [16]:

$$
\begin{aligned}
K^{n} & =\frac{A E}{L} \\
K^{s} & =\alpha K^{n}
\end{aligned}
$$

where:

$$
\begin{aligned}
& A= \begin{cases}2 r t & (2 \mathrm{D}, \text { plane strain satet, } t=1) \\
\pi r^{2} & (3 \mathrm{D})\end{cases} \\
& L= \begin{cases}R^{(1)}+R^{(2)} & \text { ball-ball contact } \\
R^{(1)} & \text { wall-ball contact }\end{cases} \\
& r= \begin{cases}\min \left(R^{(1)}, R^{(2)}\right) & \text { ball-ball contact } \\
R^{(1)} & \text { wall-ball contact }\end{cases}
\end{aligned}
$$

Furthermore, parallel bonds can be created between the balls; it provides the mechanical behavior of a finite-sized piece of cement-like material deposited between the pieces. The parallel bonds can be imagined as a set of elastic springs with constant normal and shear stiffness $\left(\bar{K}^{n}\right.$ and $\left.\bar{K}^{s}\right)$ that are uniformly distributed over the contact surfaces; these springs act in parallel with the springs of the linear component (Figure 8). Relative motion at a contact develops a force and moment within the bond material that can be related to the maximum normal and shear stresses. It is clear that if these stresses exceed their corresponding bond strength, the bond breaks and the linear contact behavior becomes active [13] [14] [15] [16]. 


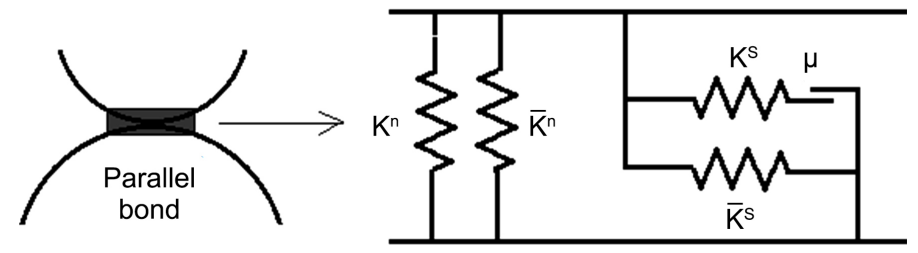

Figure 8. Springs modeling a linear contact and parallel bond [14].

The parallel-bond force is resolved into a normal and shear force $\left(\bar{F}^{n}\right.$ and $\left.\bar{F}^{s}\right)$, and the parallel-bond moment is resolved into a twisting and bending moment $\left(\bar{M}^{b}\right.$ and $\left.\bar{M}^{t}\right)$ that can be calculated by:

$$
\begin{aligned}
& \left\{\begin{array}{l}
\bar{F}^{n}=\bar{F}_{0}^{n}+\bar{K}^{n} \bar{A} \Delta \delta_{n} \\
\bar{F}^{s}=\bar{F}_{0}^{s}-\bar{K}^{s} \bar{A} \Delta \delta_{s}
\end{array}\right. \\
& \left\{\begin{array}{l}
\bar{M}^{b}=\bar{M}_{0}^{b}-\bar{K}^{n} \bar{I} \Delta \theta_{b} \\
\bar{M}^{t}=\bar{M}_{0}^{t}-\bar{K}^{s} \bar{J} \Delta \theta_{t}
\end{array}\right.
\end{aligned}
$$

where $\Delta \delta_{n}, \Delta \delta_{s}, \Delta \theta_{b}$ and $\Delta \theta_{t}$ are the relative normal, shear displacement, bend-rotation, and twist-rotation increment, respectively. Also, $\bar{A}, \bar{I}$, and $\bar{J}$ are the area, moment of inertia, and the polar moment of inertia of the bond cross-section, respectively [13] [14] [15] [16]:

$$
\begin{aligned}
& \bar{I}= \begin{cases}\frac{2}{3} t \bar{R}^{3} & (2 \mathrm{D}, \text { plane strain satet, } t=1) \\
\frac{1}{4} \pi \bar{R}^{4} & (3 \mathrm{D})\end{cases} \\
& \bar{J}= \begin{cases}0 & (2 \mathrm{D}) \\
\frac{1}{2} \pi \bar{R}^{4} & (3 \mathrm{D})\end{cases} \\
& \bar{A}= \begin{cases}2 \bar{R} t & (2 \mathrm{D}, \text { plane strain satet, } t=1) \\
\pi \bar{R}^{2} & (3 \mathrm{D})\end{cases} \\
& \bar{R}= \begin{cases}\min \left(R^{(1)}, R^{(2)}\right) & \text { ball-ball contact } \\
R^{(1)} & \text { wall-ball contact }\end{cases}
\end{aligned}
$$

The maximum normal stress $\left(\sigma_{\max }\right)$ and shear stress $\left(\tau_{\max }\right)$ are calculated as following [13] [14] [15] [16]:

$$
\begin{gathered}
\sigma_{\max }=\frac{\left\|\bar{F}^{n}\right\|}{\bar{A}}+\frac{\left\|\bar{M}^{b}\right\| \bar{R}}{\bar{I}} \\
\tau_{\max }=\frac{\left\|\bar{F}^{s}\right\|}{\bar{A}}+\left\{\begin{array}{l}
0 \\
\frac{\left\|\bar{M}^{t}\right\| \bar{R}}{\bar{J}}
\end{array}\right.
\end{gathered}
$$

\section{DEM Model of Concrete}

PFC2D software simulates macro-scale material behavior from the interactions of micro-scale components whose parameters are micro-mechanical properties of constituents, which are listed in Table 3. These micro properties cannot be 
derived directly from measurements of laboratory specimens. So, three cylindrical specimens of the concrete with $54 \mathrm{~mm}$ in diameter and $110 \mathrm{~mm}$ in height were prepared and examined via applying a standard-uniaxial-compressive test; the mean strength and Young modulus were $20 \mathrm{MPa}$ and $27 \mathrm{GPa}$, respectively. Then, to estimate properties of constituent balls and their bonding strength for the purpose of simulating the concrete, the corresponding compressive test was simulated using software; the input micro-parameters were changed until the calculated data (Young modulus and compressive strength from the DEM) matched the measured data experimentally. Table 3 gives obtained micro-mechanical parameters of concrete balls, and Figure 9(a) shows a rectangular-DEM model of concrete (with $110 \mathrm{~mm}$ in height and $54 \mathrm{~mm}$ in width) under compressive loads; it was simulated by 3602 discs bonded together and with 0.5 to $0.75 \mathrm{~mm}$ in radius [13] [14] [15] [16] [20]. Figure 9(b) shows the concrete specimen broken under the compressive test.

Table 3. Micro-mechanical properties of concrete obtained from DEM model.

\begin{tabular}{cc}
\hline \multicolumn{2}{c}{ Micro-mechanical properties } \\
Young modulus of contacts \\
Friction coefficient of contacts & $0.3 \mathrm{GPa}$ \\
Normal-to-shear stiffness ratio of contacts & 1.0 \\
Young modulus of bonds & 0.2 \\
Tensile strength of bonds & $1.6 \mathrm{MPa}$ \\
Cohesion of bonds & $2.3 \mathrm{MPa}$ \\
Normal-to-shear stiffness ratio of bonds & 1.0 \\
\hline
\end{tabular}

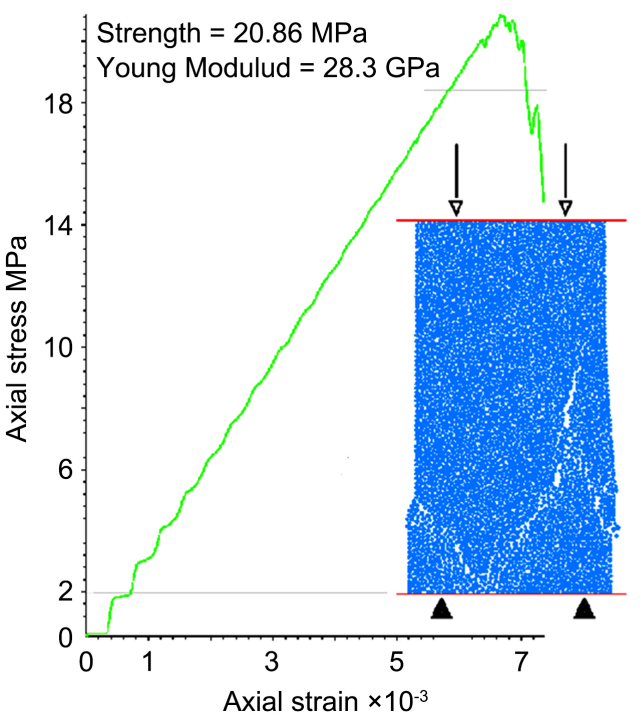

(a)

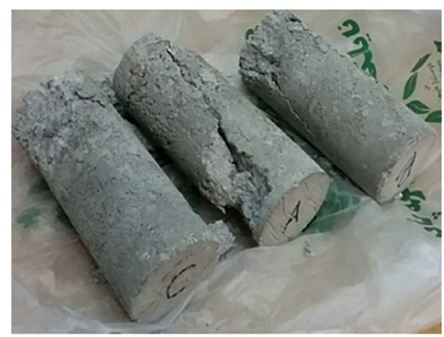

(b)

Figure 9. (a) DEM model of applying compressive loads to a concrete specimen and (b) concrete specimen broken under the compressive test. 


\section{DEM Model of Rock Bolts}

The studied rock bolts were modeled by wall elements in the PFC2D; the wall elements are rigid and can only move and interact with the particles depending on the stiffness and friction at the contact points. The concrete was simulated by 29,047 disc-shaped rigid particles with range of 0.5 to $0.75 \mathrm{~mm}$ in radius. The particles of concrete were bonded using the parallel method; the micro parameters listed in Table 3 were inputted. Figure 10 shows DEM model of bolt shells and an installed bolt in the concrete that was carried out the pull-out test. Also, Figure 11 shows the force-displacement curves of the bolts that were obtained from the PFC models; the final-pull-out strength of shell include convex edges and concave bits were equal to $85 \mathrm{KN}$ and $500 \mathrm{~N}$, respectively that were near to those obtained experimentally.

Furthermore, the reactions of earth to pull out the bolts were shown in Figure 12 as the distribution of contact forces between the concrete particles; the shell including convex edges transferred the pull-out load to an area that is larger

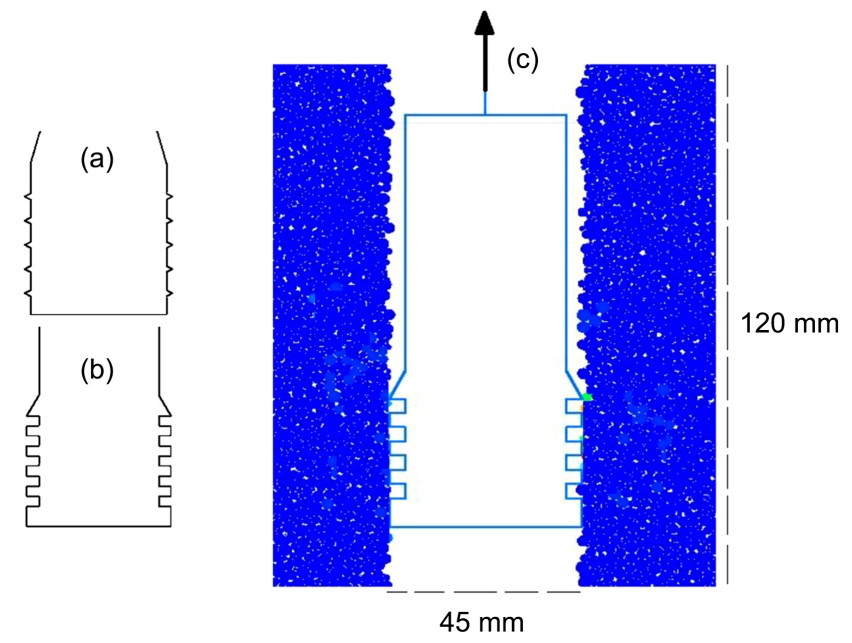

Figure 10. PFC model of bolt shells including (a) convex edges, (b) concave bits and c) an installed bolt in concrete under pull-out test.

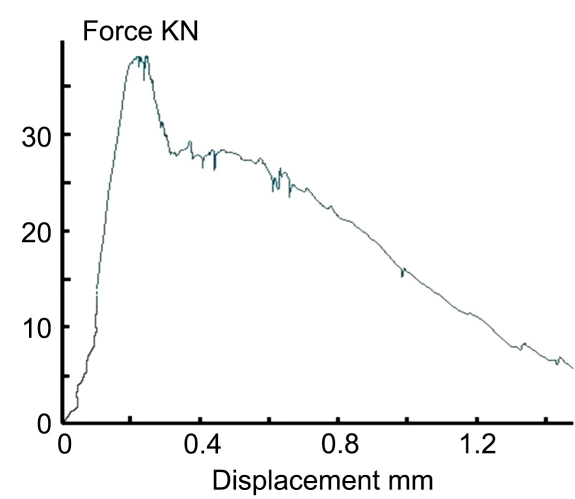

(a)

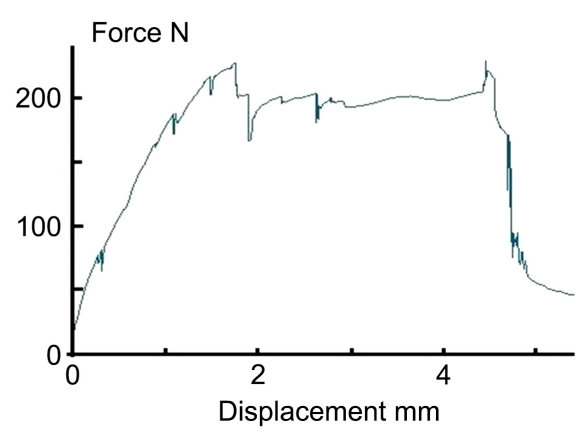

(b)

Figure 11. Force-displacement of rock bolts with shells including (a) convex edges, (b) concave bits obtained from PFC. 


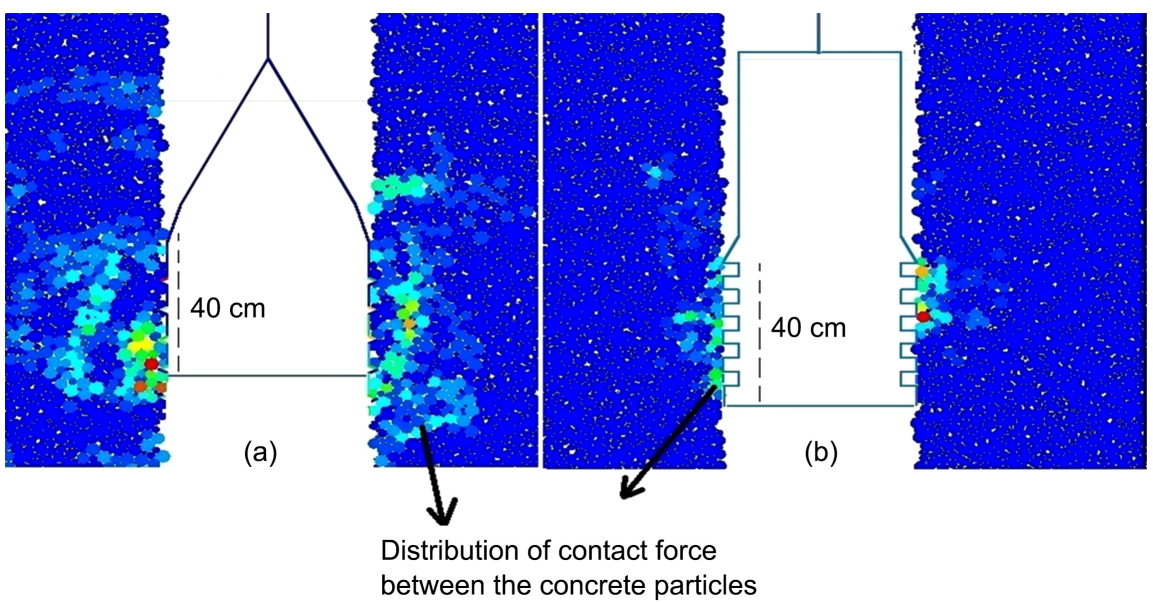

Figure 12. Distribution of contact forces due to pulling shells including (a) convex edges, (b) concave bits (All colors show the distribution of contact forces, in except of dark blue).

than the concrete region reacting to pull out the shell with concave bits. Consequently, the convex edges create higher frictional resistances than those developed by concave bits in rock structures against earth movements. On the other hand, frictional rock bolts with edges penetrating rocks improve rock strength well in active-support systems.

\section{Conclusion}

In this study, the pull-out strength of ten frictional rock bolts with expanding shells was investigated in the laboratory and then modeled using distinct element method. Five bolts included shells with convex edges while the shells of other bolts had concave bits. The experimental results showed that the strength of the rock bolts with convex edges against the pulling out process was more than that of the shells with concave bits. The DEM model confirmed that the strength depended on the shape of the shell structure; the convex edges could transfer the pull-out load to the area that is larger than the concrete region reacting to pull out the shell with concave bits. Because the shells with concave bits could not penetrate to the inner wall of holes and they couldn't create a high frictional resistance against earth movements. However, the expansion-shell-rock bolts with convex edges are so suitable to improve rock strength in an active-supporting system, because they penetrated to the inner wall and could resist against the pulling out process remarkably. Furthermore, The PFC models confirmed that the DEM modeled the reaction of earth to pulling out process of bolts and transferring applied forces on the bolt roads into the inner wall of holes very well.

\section{Acknowledgements}

The authors would like to acknowledge The University of Zanjan for the financial support. 


\section{Conflicts of Interest}

The authors declare no conflicts of interest regarding the publication of this paper.

\section{References}

[1] Hoien, A.H., Nilsen, B. and Olsson, R. (2019) Main Aspects of Deformation and Rock Support in Norwegian Road Tunnels. Tunnelling and Underground Space Technology, 86, 262-278. https://doi.org/10.1016/j.tust.2019.01.026

[2] Chen, C., Nemcik, J., Ting, T. and Aziz, N. (2013) A Study of Rock Bolting Failure Modes. International Journal of Mining Science and Technology, 23, 79-88. https://doi.org/10.1016/j.ijmst.2013.01.012

[3] Li, C.C. (2010) A New Energy-Absorbing Bolt for Rock Support in High Stress Rock Masses. International Journal of Rock Mechanics and Mining Sciences, 47, 396-404. https://doi.org/10.1016/j.ijrmms.2010.01.005

[4] Jiang, Y., Tanabasi, Y. and Huang, H. (2007) Reinforcement Mechanics of Passive Bolts in Conventional Tunneling. International Journal of Rock Mechanics and Mining Sciences, 44, 625-636. https://doi.org/10.1016/j.ijrmms.2006.10.003

[5] Uyar, G.G. and Aksoy, C.O. (2018) New Support Suggestions to High Swelling Clayey Rock Mass. Journal of Mining Science, 54, 99-110. https://doi.org/10.1134/S1062739118044087

[6] Alymenko, D.N., Solov'ev, V.A., Aptukov, V.N. and Kotlyar, E.K. (2018) System of Support for Junctions of Mine Shafts and Roadways in Salt Rocks. Journal of Mining Science, 54, 40-47. https://doi.org/10.1134/S1062739118013318

[7] Pitrakkos, T. and Tizani, W. (2013) Experimental Behavior of a Novel Anchored Blind-Bolt in Tension. Engineering Structures, 49, 905-919. https://doi.org/10.1016/j.engstruct.2012.12.023

[8] Kang, H., Wu, Y., Gao, F., Jiang, P., Cheng, P., Meng, X. and Li, Z. (2016) Mechanical Performances and Stress States of Rock Bolts under Varying Loading Conditions. Tunnelling and Underground Space Technology, 52, 138-146. https://doi.org/10.1016/j.tust.2015.12.005

[9] Tizani, W., Rahman, N.A. and Pitrakkos, T. (2013) Fatigue Life of an Anchored Blind-Bolt Loaded in Tension. Journal of Constructional Steel Research, 93, 1-8. https://doi.org/10.1016/j.jcsr.2013.10.002

[10] Wang, L., et al. (2016) Experimental Study of a Pull-Out Test of Corroded Steel and Concrete Using the Acoustic Emission Monitoring Method. Construction and Building Materials, 122, 163-170. https://doi.org/10.1016/j.conbuildmat.2016.06.046

[11] Delhomme, F. and Debicki, G. (2010) Numerical Modelling of Anchor Bolts under Pullout and Relaxation Tests. Construction and Building Materials, 24, 1232-1238. https://doi.org/10.1016/j.conbuildmat.2009.12.015

[12] Dou, L.M., Cai, W., Gong, S.Y., Han, R.J. and Liu, J. (2014) Dynamic Risk Assessment of Rock Burst Based on the Technology of Seismic Computed Tomography Detection. Journal of China Coal Society, 39, 238-244.

[13] Potyondy, D.O. and Cundall, P.A. (2004) A Bonded-Particle Model for Rock. International Journal of Rock Mechanics and Mining Sciences, 41, 1329-1364. https://doi.org/10.1016/j.ijrmms.2004.09.011

[14] Jing, L. and Stephansson, O. (2007) Fundamentals of Discrete Element Methods for Rock Engineering: Theory and Applications. Elsevier, New York. https://doi.org/10.1016/S0165-1250(07)85001-2 
[15] Refahi, A., AghazadehMohandesi, J. and Rezai, B. (2010) Discrete Element Modeling for Predicting Breakage Behavior and Fracture Energy of a Single Particle in a Jaw Crusher. International Journal of Mineral Processing, 94, 83-91. https://doi.org/10.1016/j.minpro.2009.12.002

[16] AghazadehMohandesi, J., Refahi, A., SadeghiMeresht, E. and Berenji, S. (2011) Effect of Temperature and Particle Weight Fraction on Mechanical and Micrimechanical Properties of Sand-Polyethylene Terephthalate Composites: A Laboratory and Discrete Element Method Study. Composites Part B, 42, 1461-1467. https://doi.org/10.1016/j.compositesb.2011.04.048

[17] Thenevin, I., Martin, L.B., Hassen, F.H., Schleifer, J., Lubosik, Z. and Wrana, A. (2017) Laboratory Pull-Out Tests on Fully Grouted Rock Bolts and Cable Bolts: Results and Lessons Learned. International Journal of Rock Mechanics and Mining Sciences, 9, 843-855. https://doi.org/10.1016/j.jrmge.2017.04.005

[18] Salcher, M. and Bertuzzi, R. (2018) Results of Pull Tests of Rock Bolts and Cable Bolts in Sydney Sandstone and Shale. Tunnelling and Underground Space Technology, 74, 60-70. https://doi.org/10.1016/j.tust.2018.01.004

[19] American Society for Testing and Materials (1998) Standard Test Method for Rock Bolt Anchor Pull Test, D 4435-84.

[20] Skramtajew, B.G. (1938) Determining Concrete Strength for Control of Concrete in Structures. Journal of the American Concrete Institute, 34, 285-304.

https://doi.org/10.14359/8451 